\title{
MENINGKATKAN AKTIVITAS DAN HASIL BELAJAR SISWA \\ DENGAN MENGGUNAKAN PESAN ELEKTRONIK (E-MAIL) \\ PADA KELAS IX - 1 SEMESTER I SMP NEGERI 1 PERCUT SEI TUAN \\ TAHUN AJARAN 2016/ 2017.
}

\author{
Maruap Pardede \\ Guru TIK SMP Negeri 1 Percut Sei Tuan \\ Maruap_pardede@yahoo.com
}

\begin{abstract}
ABSTRAK
Penelitian ini bertujuan untuk memecahkan permasalahan yang di hadapi selama pembelajaran TIK khusunya di SMP Negeri 1 Percut Sei Tuan, Sekaligus untuk mengetahui seberapa mampu siswa mengirim email dan meningkatkan hasil belajar siswa. Penelitian ini di lakukan selama 2 bulan yaitu pada bulan Juli sampai dengan selesai. Subjek dari Penelitian ini merupakan siswa kels IX -1 SMP Negeri 1 Percut Sei Tuan Tahun Ajaran 2016/2017 yang berjumlah 36 orang siswa/i. Penelitian ini diadakan selama 2 siklus, dengan menempatkan free test sebagai data awal sebelum melakukan instrumen yang digunakan untuk mengetahui hasil belajar siswa adalah tes hasil belajar dalam bentuk pilihan berganda dengan jumlah 20 soal. Dari hasil penelitian diperoleh nilai rata-rata pretes kelas 56,25 dan hasil tugas portofolio 62,77 . Setelah pembelajaran selesai diberikan diperoleh postes dengan hasil rata-rata kelas 73,05 dan dengan hasil potofolio 78,05.
\end{abstract}

Kata Kunci : Belajar, hasil belajar, pesan elektronik (email).

\section{PENDAHULUAN}

Di dalam pembelajaran siswa dituntut agar dapat mencapai kompetensi. Seperti yang tercantum dalam Permendiknas No.23 Tahun 2006. Kompetensi adalah kemampuan bersikap, berpikir, dan bertindak secara konsisten sebagai perwujudan dari pengetahuan, sikap, dan keterampilan yang dimiliki peserta didik. Untuk mencapai kompetensi ini tidak hanya tertumpu pada siswa saja namun guru serta elemen-elemen yang ada juga harus diikut sertakan

TIK merupakan salah mata pembelajaran yang diajarkan di tingkat pendidikan dasar sampai menengah. Pada pendidikan SMP, kurikulum TIK bertujuan untuk memberikan kemampuan kepada siswa untuk: 1) Memahami TIK, 2) Mengembangkan keterampilan untuk memanfaatkan TIK, 3) Mengembangkan sikap kritis, kreatif, apresiatif dan mandiri dalam penggunaan TIK, 4) Menghargai karya cipta di bidang TIK. Sedangkan pembelajaran TIK di SMA mencakup aspekaspek sebagai berikut: 1) Perangkat keras dan perangkat lunak yang digunakan untuk mengumpulkan, menyimpan, memanipulasi, dan menyajikan informasi, 2) Penggunaan alat bantu untuk memproses dan memindahkan data dari satu perangkat ke perangkat lainnya, 3) Menciptakan karya baru dari berbagai data yang diperoleh dengan menggunakan TIK dan berbagai perangkat lunak yang relevan.

Pelaksanaan pembelajaran TIK di tuntut agar dilaksanakan secara ilmiah untuk menumbuhkan kemampuan berpikir, bekerja dan bersikap ilmiah serta berkomunikasi sebagai salah satu aspek yang penting dalam pembelajaran. Selama proses pembelajaran, guru sering sekali mendapati tidak jarang dari murid-murid yang masih belum paham dari materi pembelajaran yang diajarkan walaupun sudah melakukan praktik langsung di kelas. Siswa juga tidak menunjukkan aktivitas yang berarti dan partisipasi dalam proses pembelajaran. Siswa lebih banyak menunggu penjelasan dari guru tentang materi yang sedang dipelajari. 
Rendahnya kualitas hasil belajar TIK siswa di SMP Negeri 1 Percut Sei Tuan diakibatkan banyaknya siswa beranggapan bahwa TIK adalah pelajaran yang sangat membosankan dan terlalu menganggap sepele akan pelajaran yang dipelajari, mereka beranggapan bisa belajar sendiri dengan otodidak. Kondisi nyata di sekolah muridmurid hanya tertarik pada praktikum nya saja. Tanpa mau tertarik terhadap teori yang di sampaikan oleh gurunya. Jelas dari gambaran tersebut bahwa proses pembelajaran TIK menjadi tidak efektif, dan akibatnya bahwa target kurikulum menjadi sangat rendah.

Berdasarkan uraian latar belakang di atas, maka dalam penelitian ini penulis mencoba menerapkannya dalam upaya meningkatkan hasil belajar TIK siswa khususnya pada sub materi pokok tentang pesan elektronik (email). Dengan demikian penelitian ini dirumuskan dengan judul: "Meningkatkan Aktivitas dan Hasil Belajar Siswa Dalam Menggunakan Pesan Elektronik (E-Mail) Pada Kelas IX - 1 Semester I SMP Negeri 1 Percut Sei Tuan Tahun Ajaran 2016/ 2017”.

\section{KAJIAN TEORITIS}

Jams (1996:21) media pembelajaran siswa merupakan faktor utama yang menentukan keterlibatan siswa secara aktif dalam belajar. Selanjutnya aktivitas belajar siswa berhubungan dengan perhatian siswa. Perbedaannya adalah aktivitas belajar siswa lebih menetap sedangkan perhatian sifatnya lebih sementara dan adakalanya menghilang. Dalam proses belajar siswa, perhatian memegang peranan penting.

Risk (2002:42) dalam bukunya "No learning takes place without attention." mengatakan proses pembelajaran akan berjalan lancar bila siswa memiliki minat yang besar yang menimbulkan perhatiannya dalam belajar. Oleh karena itu, guru perlu membangkitkan minat siswa-siswanya agar pelajaran yang diberikan mudah dipahami sehingga mereka terlibat aktif dalam pembelajaran.

Ibrahim (2002:45) mengemukakan beberapa upaya menarik aktivitas belajar siswa dalam proses belajar mengajar dipengaruhi oleh minat dan kebutuhan siswa, sebab keduanya akan menjadi penyebab timbulnya perhatian. Sesuatu yang menarik minat dan dibutuhkan siswa, akan menarik perhatiannya, dengan demikian mereka akan bersungguh-sungguh dalam belajar.

$$
\text { Sementara Djamarah (1995:25) }
$$
mengemukakan upaya-upaya yang dapat dilakukan guru untuk membangkitkan keaktifan siswa dalam belajar, yaitu:

a. Membangkitkan adanya suatu kebutuhan.

b. Menghubungkan dengan persoalan pengalaman yang lampau.

c. Memberi kesempatan untuk mendapatkan hasil yang baik.

d. Menggunakan berbagai macam bentuk mengajar.

Belajar pada dasarnya merupakan peristiwa yang bersifat individual yakni terjadinya perubahan tingkah laku sebagai dampak dari pengalaman individu. Menurut Sudjana (2009:25) hasil belajar pada dasarnya adalah perubahan tingkah laku atau keterampilan yang berupa pengetahuan, pemahaman, sikap dan aspek lain lewat serangkaian kegiatan membaca, mengamati, mendengar, meniru, menulis, dan lain sebagainya, sebagai bentuk pengalaman individu dengan lingkungan.

Menurut A. Rooyakkers (1984:13) mengatakan bahwa: "Proses mengajar adalah menyampaikan bahan pelajaran yang berarti melaksanakan beberapa kegiatan. Kegiatan tersebut tidak ada gunanya jika tidak mengarah pada tujuan tertentu"

Sementara itu, Ahmadi (2008:35) mengemukakan bahwa hasil belajar adalah hasil yang dicapai dalam suatu usaha, dalam hal ini usaha hasil belajar berupa perwujudan prestasi belajar siswa yang dapat dilihat pada nilai setiap mengikuti tes.

Berdasarkan uraian-uraian tersebut, peneliti menyimpulkan bahwa Hasil Belajar Siswa adalah sesuatu yang diadakan oleh usaha yang dilakukan siswa melalui suatu aktivitas mental/fisik yang berlangsung dengan interaksi aktif dengan lingkungan.

Menurut Mustakini (2009:34) bahwa email merupakan singkatan dari Electronic Mail, atau dalam bahasa Indonesia nya Surat Elektronik, yaitu surat yang pengirimannya menggunakan sarana elektronik yaitu dengan 
jaringan internet, dengan surat elektronik atau email seseorang dapat mengirim naskah teks, gambar, atau bahkan mengirimkan aplikasi atau file kepada seseorang yang tentunya juga memiliki email (surat elektronik) dalam waktu yang sangat singkat. Karena email ini menggunakan jaringan internet, maka alamatnya pun juga menyesuaikan dengan penyedia layanan email di internet. Contoh penyedia layanan email adalah www.mail.yahoo.com, www.mail.google.com, dll. penyedia email biasanya menyediakan dua layanan, yaitu layanan berbayar dan layanan gratis.

Menurut Moekijat dalam Prasojo (2011:152) bahwa surat elektronik sudah mulai dipakai pada tahun 1960-an. Pada saat itu Internet belum terbentuk, yang ada hanyalah kumpulan mainframe yang terbentuk sebagai jaringan. E-mail bermula pada tahun 1968, di sebuah perusahaan yang bernama Bolt Beranek and Newman (BBN) dikontrak oleh Departemen Pertahanan AS untuk menyelesaikan proyek yang disebut ARPANET (Advanced Research Projects Agency Network) yang kemudian berubah menjadi Internet. ARPANET sendiri adalah proyek yang semula bertujuan untuk menciptakan sebuah metode komunikasi antara institusi militer dan pendidikan satu sama lain.

Kemudian pada tahun 1971, seorang insinyur bernama Ray Tomlinson ditugaskan dalam program yang disebut SNDMSG. Program ini bukanlah program baru, karena sebenarnya program tersebut sudah ada sejak sekian tahun silam. Dilihat dari standar masa kini, program tersebut bisa dikatakan lebih primitif. Apa yang bisa dilakukan oleh program tersebut hanyalah saling mengirim pesan kepada sesama pengguna dalam satu mesin yang sama. Ketika pengguna membuat pesan / dokumen dalam bentuk teks, selanjutnya pesan tersebut akan dikirimkan ke dalam kotak surat yang ada pada mesin itu.

Menurut Mulyanto (2009:29) bahwa program SNDMSG yang bisa digunakan untuk meninggalkan pesan pada sebuah komputer, sehingga orang lain yang memakai komputer tersebut dapat membaca pesan yang ditinggalkan. Lalu, dia melanjutkan eksperimennya dengan menggunakan file protokol yang dinamakan CYPNET sehingga program SNDMSG tadi bisa mengiri pesan ke komputer lain yang berada di dalam jaringan ARPANET. Itulah awal mula terciptanya sebuah 'e-mail'. Pesan email yang pertama kali dikirim Ray dan merupakan e-mail yang pertama kalinya di dunia adalah "QWERTYUIOP". Selanjutnya pada tahun 1972, Ray memperkenalkan icon '@) yang berarti “at" atau "pada" sebagai identitas email untuk memisahkan user id dan domain sebuah alamat email.

\section{METODOLOGI PENELITIAN}

Penelitian ini dilakukan di SMP Negeri 1 Percut Sei Tuan yang beralamat Jalan Mesjid Kecamatan Percut pada kelas IX-1 SMP Negeri 1 Percut Sei Tuan pada semester 1 tahun pelajaran 2016/2017. Waktu penelitian dilaksanakan selama dua bulan terhitung mulai tanggal 2 Agustus 2016 sampai tanggal 31 September 2016. Penelitian tindakan kelas ini dilaksanakan dalam dua siklus. Siklus I dilaksanakan dalam tiga kali tindakan (pertemuan) dengan alokasi waktu 2 x 40 menit, dan siklus II dilaksanakan dalam tiga kali pertemuan dengan alokasi waktu 2 x 40 menit. Berdasarkan pernyataan diatas penelitian ini mengambil seluruh populasi yang ada menjadi sampel yaitu sebanyak 36 orang pada kelas IX-1.

Subjek penelitian ini adalah siswa kelas IX-1 SMP Negeri 1 Percut Sei Tuan pada semester I tahun pelajaran 2016/2017. Penelitian ini dilakukan oleh peneliti dan berkolaborasi dengan dua orang guru Teknolologi Informasi dan Komunikasi (TIK) SMP Negeri 1 Percut Sei Tuan. Jumlah siswa di kelas IX-1 sebanyak 36 orang yang terdiri dari 14 laki-laki dan 22 perempuan. Peneliti mengambil subjek penelitian siswa kelas IX-1 mengingat karakteristiknya cenderung lebih pasif dibandingkan kelas lainnya dan berdasarkan dari hasil belajar pada materi sebelumnya masih dianggap relatif rendah.

Penelitian ini dilakukan bermaksud untuk menemukan informasi tentang perancangan pembelajaran untuk meningkatkan hasil belajar TIK pada siswa/i 
SMP Negeri 1 Percut Sei Tuan Tahun Ajaran 2016 / 2017. Metode yang digunakan adalah metode penelitian tindakan kelas yaitu dengan teknik siklus.

Desain penelitian yang digunakan sesuai dengan kaidah-kaidah penelitian tindakan kelas (Classroom Action Research) yang memiliki beberapa karakteristik diantaranya didasarkan atas masalah yang dihadapi guru dalam pembelajaran, dilakukan secara kolaboratif melalui kerja sama dengan pihak lain, peneliti sekaligus sebagai praktisi yang melakukan refleksi, bertujuan memecahkan masalah atau meningkatkan mutu pembelajaran, dilaksanakan dalam rangkaian langkah yang terdiri dari beberapa siklus, yang diteliti adalah tindakan yang dilakukan, meliputi efektifitas metode, teknik, atau proses pembelajaran (termasuk perencanaan, pelaksanaan dan penilaian), dan tindakan yang dilakukan adalah tindakan yang diberikan guru kepada peserta didik.

Dalam Karwono (2008), prosedur penelitian tindakan kelas merupakan proses pengkajian melalui system berdaur dari berbagai kegiatan pembelajaran yang terdiri dari beberapa tahapan sebagai berikut:

a. Pengembangan focus masalah penelitian.

b. Pelaksanaan tindakan perbaikan.

c. Pelaksanaan tindakan perbaikan, observasi dan interoretasi.

d. Analisis dan refleksi.

e. Perencanaan tindakan lanjut.

\section{HASIL DAN PEMBAHASAN}

\section{Hasil Penelitian}

Hasil penelitian diuraikan dalam tahapan yang berupa siklus-siklus pembelajaran yang dilakukan dalam proses belajar mengajar di kelas. Dalam penelitian ini dilakukan dalam dua siklus sebagaimana pemaparan berikut ini.

\section{Siklus Pertama (dua pertemuan)}

Siklus pertama terdiri dari empat tahap, yaitu perencanaan, pelaksanaan, observasi dan refleksi, seperti berikut:

\section{Perencanaan (Planning)}

Kegiatan yang dilakukan dalam tahap perencanaan adalah : a. Mempersiapkan materi ajar berdasarkan kompetensi dasar yang akan dipelajari siswa

b. Pengamatan kondisi sekolah dengan penerapan internet yang ada di sekolah mendukung adanya pembelajaran berbasis internet

c. Membuat lembar observasi untuk mengamati proses pembelajaran

d. Menyusun alat evaluasi untuk mengetahui kemampuan siswa

\section{Pelaksanaan Tindakan}

Tindakan pelaksanaan dalam tahap ini adalah melaksanakan rencana pembelajaran yang telah direncanakan berupa penggunaan pesan elektronik (email) bagi siswa yang bertujuan meningkatkan hasil belajar siswa dalam penggunaan email. Siswa diminta dapat menjelaskan tentang bagian - bagian dari wall yang ada di email dan selanjutnya siswa diminta untuk mencoba mengirim beberapa berkas melalui pesan elektronik

(email) kepada siswa lainnya.

Pada saat awal siklus pertama pelaksanaan belum sesuai dengan rencana. Hal ini disebabkan:

a. Sebagian siswa belum terbiasa mengirim email (pesan elektronik)

b. Sebagian siswa belum memahami langkah-langkah dalam mengirim email (pesan elektronik).

Untuk mengatasi masalah di atas dilakukan upaya sebagai berikut:

1) Guru dengan intensif memberi pengertian kepada siswa tentang kondisi belajar mandiri, kerjasama, serta pengetahuan awal siswa terhadap materi pelajaran.

2) Guru membantu siswa yang belum memahami langkah-langkah dalam mengirim berkas melalui email

Pada akhir siklus pertama dari hasil pengamatan guru dapat disimpulkan:

a. Siswa belum terbiasa dengan metode pembelajaran yang disajikan.

b. Siswa tidak mampu memahami materi pembelajaran yang disampaikan guru secara utuh dan menyeluruh.

c. Siswa tidak memiliki sumber belajar yang cukup untuk mendukung proses pembelajaran. 
Observasi dan Evaluasi (Observation and Evaluation)

Hasil yang diperoleh siswa pada siklus I berupa hasil belajar siswa kelas IX-1 SMP Negeri 1 Percut Sei Tuan tahun pelajaran 2016/2017 dalam pembelajaran TIK pada materi pelajaran pesan elektronik dapat dilihat pada tabel berikut: Tabel 1

Tabel 1

Perolehan Skor Pengamatan Hasil Belajar Siswa dalam KBM Siklus I

\begin{tabular}{|c|l|c|c|c|c|}
\hline \multirow{2}{*}{ No } & \multirow{2}{*}{ Nama } & \multicolumn{2}{|c|}{ Siklus I } & Fortofolio \\
\cline { 2 - 6 } & & Skor & Keterangan & Skor & Keterangan \\
\hline 1 & Ari Putra & 65 & R & 70 & T \\
\hline 2 & Alvin Syahri & 50 & SR & 60 & TD \\
\hline 3 & Citra Ananda & 60 & R & 50 & TD \\
\hline 4 & Dini Pratiwi & 50 & SR & 60 & TD \\
\hline 5 & Devi Suryani & 55 & SR & 55 & TD \\
\hline 6 & Deliana Sari & 40 & SR & 50 & TD \\
\hline 7 & Dini Armayana & 60 & R & 60 & TD \\
\hline 8 & Dicky Suhendro & 70 & S & 75 & T \\
\hline 9 & Dian Novita Sari & 50 & SR & 60 & TD \\
\hline 10 & Devi Anuardianty & 60 & R & 70 & T \\
\hline 11 & Dira Roza Utami & 55 & SR & 60 & TD \\
\hline 12 & Hefni Ambar & 55 & SR & 60 & TD \\
\hline 13 & Helen Wulandari & 60 & R & 70 & T \\
\hline 14 & Hasbi Ramadhan & 50 & SR & 60 & TD \\
\hline 15 & Indah Lestari & 55 & SR & 65 & TD \\
\hline 16 & Ibnu Hazmi Dana & 55 & SR & 65 & TD \\
\hline 17 & Julia Maisyaro & 70 & S & 75 & T \\
\hline 18 & Kukuh Pambadi & 50 & SR & 60 & TD \\
\hline 19 & Linda Azhari & 60 & R & 70 & T \\
\hline 20 & M.Hidayah & 55 & SR & 65 & TD \\
\hline 21 & M.yogi Pratama & 65 & R & 65 & TD \\
\hline 22 & M.Yasin Hidayat & 55 & SR & 55 & TD \\
\hline 23 & M.Fazar & 50 & SR & 60 & TD \\
\hline 24 & Muamar Munthe & 55 & SR & 65 & TD \\
\hline 25 & M.Rizki & 70 & S & 70 & T \\
\hline 26 & M.Raja Lurus & 60 & R & 60 & TD \\
\hline 27 & Nurlela & 50 & SR & 60 & TD \\
\hline 28 & Nur Intan & 55 & SR & 65 & TD \\
\hline 29 & Nur Azizah & 50 & SR & 60 & TD \\
\hline 30 & Puji Syahputra & 55 & SR & 65 & TD \\
\hline 31 & Riski Fadli & 65 & R & 65 & TD \\
\hline 32 & Rikki Setiawan & 60 & R & 60 & TD \\
\hline 33 & Septi Wahyuni & 50 & SR & 60 & TD \\
\hline 34 & Shelli Anggraini & 55 & SR & 65 & TD \\
\hline 35 & Sri Ayuandika & 55 & SR & 65 & TD \\
\hline 36 & Surya Bagus & 50 & SR & 60 & TD \\
\hline Keteray & & & & \\
\hline
\end{tabular}

Keterangan :

$\mathrm{S}=$ Sedang,

$\mathrm{R}=$ Rendah ,

$\mathrm{SR}=$ Sangat Rendah

$\mathrm{T}=$ Tuntas,

$\mathrm{TD}=$ Tidak Tuntas 


\section{Hasil Observasi Siklus 1}

Berdasarkan tabel di atas :

a. maka siswa yang mencapai KKM hanya 3 orang yaitu $10 \%$, sedangkan yang belum tuntas mencapai $90 \%$ yaitu 33 orang, dalam kegiatan belajar mengajar pada siklus pertama masih tergolong rendah dengan perolehan skor 50 sedangkan skor idealnya adalah 70 batas KKM. Hal ini terjadi karena lebih banyak siswa yang tidak paham dengan materi pembelajaran yang disampaikan. Penguasaan siswa terhadap materi pembelajaran.

b. Selain aktivitas guru dalam KBM, penguasaan siswa terhadap materi pembelajaran pun masih tergolong kurang. Dari skor ideal 100, skor perolehan rata-rata hanya mencapai 56,25 atau $56,25 \%$. Selain dari nilai hasil tes belajar siswa nilai lain yang mendukung tentang rendahnya pembelajaran dalam pesan elektronik (email) adalah nilai dari uji rubrik prosedur portofolio menjelaskan masih banyak siswa yang belum tuntas dalam mengirim email maupun menggunakan email. Ini dibuktikan hanya 7 orang siswa yang tuntas dalam menggunakan email dan mampu mengirim email, sisanya ada 29 orang siswa yang masih belum mampu menggunakan email.

\section{Refleksi dan Perencanaan Ulang (Reflecting and Replanning)}

Adapun kegagalan yang terjadi pada siklus pertama adalah sebagai berikut :

a. Siswa belum terbiasa dengan singkatan dan berbagai macam jenis web dalam internet. Hal ini diperoleh dari hasil observasi terhadap hasil belajar siswa dengan tes hasil belajar siswa pada KBM hanya mencapai $56,25 \%$.

b. Sebagian siswa belum terbiasa dengan kondisi belajar dengan menggunakan dan mengirim email kepada teman lainnya ataupun pengguna email lainnya. Hal ini bisa dilihat dari hasil observasi terhadap rubrik uji portofolio siswa dalam KBM hanya mencapai 7 orang yang tuntas dari 36 orang sisw. Hal ini karena siswa kurang mampu dalam mempresentasikan kegiatan.
Untuk memperbaiki kelemahan dan mempertahankan keberhasilan yang telah dicapai pada siklus pertama, maka pada pelaksanaan siklus kedua dapat dibuat perencanaan sebagai berikut: (a) Memberikan motivasi kepada siswa agar lebih aktif lagi dalam pembelajaran, (b) Lebih intensif membimbing siswa yang mengalami kesulitan, dan (c) Memberikan siswa kesempatan untuk mengulang pembelajaran dalam menggunakan email.

\section{Siklus Kedua (satu pertemuan)}

Pada siklus kedua ini, mulai dilakukan pembelajaran ulang tentang materi yang ada di internet dan cara mengirim email yang benar. Terdiri dari empat tahap yaitu perencanaan, pelaksanaan, observasi, dan reflecting serta replaning.

\section{Perencanaan (Planing)}

Planning pada siklus kedua ini berdasarkan hasil dari siklus pertama yaitu:

a. Melakukan analisis terhadap standar kompetensi dan kompetensi dasar yang akan disampaikan pada siswa.

b. Membuat rencana pembelajaran.

c. Membuat lembar observasi siswa

d. Membuat tugas portofolio dari siklus pertama.

e. Membuat instrumen yang akan digunakan

f. Menyusun alat evaluasi pembelajaran.

\section{Pelaksanaan (Acting)}

Pada saat awal siklus kedua pelaksanaan belum sesuai dengan rencana. Hal ini disebabkan:

a. Tugas diberikan guru kepada siswa dengan menggunakan agar mampu menemukan/membuat pasangan yang sesuai. Siswa secara mandiri menunjukkan penguasaan materi pelajaran yang telah disampaikan guru melalui pencarian pasangan kartu yang sesuai.

b. Sebagian siswa merasa termotivasi untuk bertanya dan menanggapi model pembelajaran yang telah dilakukan.

c. Suasana pembelajaran yang efektif dan menyenangkan sudah mulai tercipta.

\section{Observasi dan Evaluasi (Observation and Evaluation)}


Hasil yang diperoleh siswa sebelum diadakan siklus berupa hasil belajar siswa kelas IX-1 SMP Negeri 1 Percut Sei Tuan tahun pelajaran 2016/2017 dalam pembelajaran TIK pada materi pelajaran pesan elektronik belum mencapai Kriteria Ketuntasan Minimal dengan nilai 75. Hasil belajar siswa pada postes dan fortofolio pada siklus II, sudah semua siswa tuntas karena semua siswa mendapatkan nilai di atas Kriteria Ketuntasan Minimal. Nilai terendah yang diperoleh siswa 70 dan nilai tertinggi yang diperoleh siswa adalah 85. Hasil observasi aktivitas siswa dalam KBM selama siklus kedua dapat dilihat pada tabel 2 berikut ini :

Tabel 2. Nilai Postes Tes hasil Belajar Siswa dan Fortofolio Siswa Siklus II

\begin{tabular}{|c|l|c|c|c|c|}
\hline \multirow{2}{*}{ No } & \multicolumn{1}{|c|}{ Nama } & \multicolumn{2}{|c|}{ Postes } & \multicolumn{2}{c|}{ Fortofolio } \\
\cline { 3 - 6 } & & Skor & keterangan & Skor & Keterangan \\
\hline 1 & Ari Putra & 75 & $\mathrm{~S}$ & 80 & $\mathrm{~T}$ \\
\hline 2 & Alvin Syahri & 70 & $\mathrm{~S}$ & 70 & $\mathrm{~T}$ \\
\hline 3 & Citra Ananda & 70 & $\mathrm{~S}$ & 70 & $\mathrm{~T}$ \\
\hline 4 & Dini Pratiwi & 70 & $\mathrm{~S}$ & 70 & $\mathrm{~T}$ \\
\hline 5 & Devi Suryani & 75 & $\mathrm{~S}$ & 75 & $\mathrm{~T}$ \\
\hline 6 & Deliana Sari & 80 & $\mathrm{~T}$ & 80 & $\mathrm{~T}$ \\
\hline 7 & Dini Armayana & 80 & $\mathrm{~T}$ & 80 & $\mathrm{~T}$ \\
\hline 8 & Dicky Suhendro & 80 & $\mathrm{~T}$ & 85 & $\mathrm{~T}$ \\
\hline 9 & Dian Novita Sari & 70 & $\mathrm{~S}$ & 80 & $\mathrm{~T}$ \\
\hline 10 & Devi Anuardianty & 65 & $\mathrm{R}$ & 80 & $\mathrm{~T}$ \\
\hline 11 & Dira Roza Utami & 65 & $\mathrm{R}$ & 80 & $\mathrm{~T}$ \\
\hline 12 & Hefni Ambar & 65 & $\mathrm{R}$ & 70 & $\mathrm{~T}$ \\
\hline 13 & Helen Wulandari & 70 & $\mathrm{~S}$ & 80 & $\mathrm{~T}$ \\
\hline 14 & Hasbi Ramadhan & 60 & $\mathrm{R}$ & 80 & $\mathrm{~T}$ \\
\hline 15 & Indah Lestari & 75 & $\mathrm{~S}$ & 85 & $\mathrm{~T}$ \\
\hline 16 & Ibnu Hazmi Dana & 75 & $\mathrm{~S}$ & 75 & $\mathrm{~T}$ \\
\hline 17 & Julia Maisyaro & 80 & $\mathrm{~T}$ & 85 & $\mathrm{~T}$ \\
\hline 18 & Kukuh Pambadi & 60 & $\mathrm{R}$ & 70 & $\mathrm{~T}$ \\
\hline 19 & Linda Azhari & 70 & $\mathrm{~S}$ & 80 & $\mathrm{~T}$ \\
\hline 20 & M.Hidayah & 65 & $\mathrm{R}$ & 75 & $\mathrm{~T}$ \\
\hline 21 & M.yogi Pratama & 85 & $\mathrm{~T}$ & 75 & $\mathrm{~T}$ \\
\hline 22 & M.Yasin Hidayat & 65 & $\mathrm{R}$ & 85 & $\mathrm{~T}$ \\
\hline 23 & M.Fazar & 70 & $\mathrm{~S}$ & 80 & $\mathrm{~T}$ \\
\hline 24 & Muamar Munthe & 75 & $\mathrm{~S}$ & 85 & $\mathrm{~T}$ \\
\hline 25 & M.Rizki & 80 & $\mathrm{~T}$ & 80 & $\mathrm{~T}$ \\
\hline 26 & M.Raja Lurus & 70 & $\mathrm{~S}$ & 80 & $\mathrm{~T}$ \\
\hline 27 & Nurlela & 70 & $\mathrm{~S}$ & 80 & $\mathrm{~T}$ \\
\hline 28 & Nur Intan & 65 & $\mathrm{R}$ & 85 & $\mathrm{~T}$ \\
\hline 29 & Nur Azizah & 70 & $\mathrm{~S}$ & 80 & $\mathrm{~T}$ \\
\hline 30 & Puji Syahputra & 75 & $\mathrm{~S}$ & 75 & $\mathrm{~T}$ \\
\hline 31 & Riski Fadli & 75 & $\mathrm{~S}$ & 75 & $\mathrm{~T}$ \\
\hline 32 & Rikki Setiawan & 70 & $\mathrm{~S}$ & 80 & $\mathrm{~T}$ \\
\hline 33 & Septi Wahyuni & 80 & $\mathrm{~T}$ & 70 & $\mathrm{~T}$ \\
\hline 34 & Shelli Anggraini & 85 & $\mathrm{~T}$ & 75 & $\mathrm{~T}$ \\
\hline 35 & Sri Ayuandika & 85 & $\mathrm{~T}$ & 75 & $\mathrm{~T}$ \\
\hline 36 & Surya Bagus & 90 & $\mathrm{ST}$ & 80 & \\
\hline
\end{tabular}


a. Hasil evaluasi penguasaan siswa terhadap materi pembelajaran pada siklus kedua juga tergolong sedang yakni dari nilai skor ideal 100 nilai rata-rata skor perolehan adalah 73,05 atau 73,05\%.

b. Hasil Ulangan uji rubrik prosedur dengan menggunakan portofolio juga mengalami peningkatan dari yang sebelumnya yaitu 62,7 menjadi 78,05 setelah dilakukan pembelajaran dengan portofolio.

\section{Refleksi (Reflecting)}

Keberhasilan yang diperoleh dalam siklus kedua adalah (a) Hasil belajar siswa dalam KBM sudah lebih mengenal macam macam web yang ada di inernet. Siswa mampu membangun pemahaman dan kerjasama untuk menyelesaikan tugas yang diberikan guru. Siswa mulai mampu berpartisipasi dalam kegiatan pembelajaran dan tepat waktu dalam melaksanakannya. Siswa mulai mampu mempresentasikan pemahaman dengan baik. Hasil ini dapat dilihat dari data observasi terhadap hasil belajar siswa siswa meningkat dari $56,25 \%$ pada siklus pertama menjadi $73,05 \%$ pada siklus kedua, dan (b) Meningkatnya aktivitas guru dalam melaksanakan evaluasi terhadap kemampuan siswa menguasai materi pembelajaran, berdasarkan hasil evaluasi dari pengerjaan tugas portofolio siswa mengenai materi pembelejaran tentang pesan elektronik (email) 62,7 pada siklus pertama meningkat menjadi 78,05 pada siklus kedua.

\section{Pembahasan Penelitian}

Berdasarkan analisis data diperoleh bahwa setelah dilakukan penelitian ini selama 2 siklus, dengan menempatkan free test sebagai data awal sebelum melakukan instrumen yang digunakan untuk mengetahui hasil belajar siswa adalah tes hasil belajar dalam bentuk pilihan berganda dengan jumlah 20 soal. Dari hasil penelitian diperoleh nilai rata-rata pretes kelas 56,25 dan hasil tugas portofolio 62,77. Setelah pembelajaran selesai diberikan diperoleh postes dengan hasil rata-rata kelas 73,05 dan dengan hasil potofolio 78,05. Dengan demikian diperoleh ada peningkatan hasil belajar siswa yang signifikan dalam penggunaan internet dan email dalam mengirim berkas

\section{KESIMPULAN}

Berdasarkan hasil analisis data dapat ditarik kesimpulan bahwa hasil belajar siswa menggunakan dalam pembelajaran internet pada materi pokok program pesan elektronik kelas IX-1 SMP Negeri 1 Percut Sei Tuan memiliki rata-rata 56,25. Hasil observasi belajar siswa setelah dilakukan siklus kedua terjadi peningkatan dalam pembelajaran internet yaitu sebesar 73,05. Berdasarkan hasil rubrik uji prosedur tugas siswa dengan menggunakan fotofolio tentang pesan elektronik terjadi peningkatan dari 62,7 pada siklus I menjadi 78,05 pada siklus II. Berdasarkan kesimpulan diatas terdapat peningkatan hasil pembelajaran siswa dalam menggunakan pesan elektronik dan pembelajaran tentang internet.

\section{DAFTAR PUSTAKA}

Ahmadi, Abu dan Widodo Supriyono. 2008. Psikologi Belajar, Jakarta: Rineka Cipta,

A. Rooijakkers. 1991.Mengajar Sukses, PT. Grasindo : Jakarta

Daradjatd Z. 1995. Metodologi Pengajaran Bahasa. Jakarta: Gramedia Pustaka.

Djamarah. 1995. Mengaktifkan Belajar Siswa Dalam Proses Belajar Mengajar. Jakarta: Gramedia Pustaka.

Ibrahim, S. 2002. Media Pembelajaran. Bandung: CV. Wacana Prima.

Jams, W. 1996. Learning Media for Students . Bandung : Citra Aditya Bhakti.

Mustakini, 2009. Sistim Informasi Teknologi, Yogyakarta, Andi Offset

Mulyanto, Agus 2009. Sistim Informasi konsep dan Aplikasi, Yokyakarta: Pustaka pelajar

Risk, T. 2002. Media Pendidikan, Pengertian, Pengembangan dan Pemanfaatannya. Jakarta : Karya Grafindo Persada

Sujana, Nana, 2009. Penelitian Proses Hasil Belajar, Bandung: Remaja Rosdakarya. 
Jurnal Pendidikan Teknologi dan Kejuruan: Vol. 20 No. 2 November 2018 